\title{
The Rate of Work done with an Egyptian Shadouf.
}

\author{
By Dr. J. S. Haldane, F.R.S., and Dr. Yandell Henderson.
}

THE $\mathrm{E}$ shadouf is a man-power apparatus which from time immemorial has been used in raising water from the Nile or from canals, etc., for local irrigation purposes in Egypt. Great numbers of them can be seen in operation throughout all parts of Upper Egypt, and there appears to be little tendency towards their displacement by power-driven pumps.

With a shadouf water is lifted, usually about ten or eleven feet, in a goat-skin bucket, and delivered into a water-channel at the higher level. During low Nile in Upper Egypt, three shadoufs, or pairs of shadoufs, working in series, are commonly employed to lift water from the Nile level to that of the adjoining land. The bucket (Fig. I) is carried on a wooden hook lashed to a light upright pole of tamarisk wood. This pole is attached at its upper end by rope to one end of a light beam made from a branch, or two branches lashed together, of acacia wood, which is sufficiently strong and rigid to support the weight of the bucket without much bending. At about three-fourths of the distance to the lower end, the beam is pierced by a hole through which passes a wooden pin on which the beam is pivoted. This pin is suspended by short cords from a stout wooden bar, of which the ends rest on two upright pillars consisting of either wood or maize-stalks and dried mud. Round the other end of the beam is plastered a globular mass of dried mud and chopped straw to

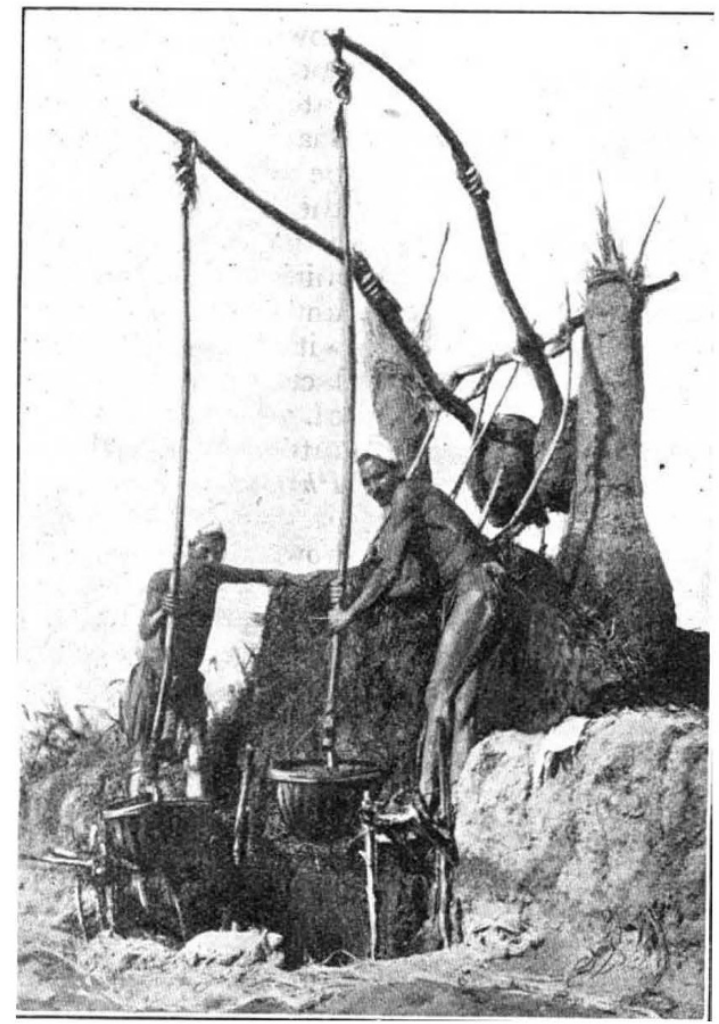

Fig. I. - Pair of shadoufs working in parallel. After a photograph by Messrs. Gaddis and Seif, Luxor.

During a recent visit to Egypt we took the opportunity of measuring the rate of work done in raising water by means of a shadouf. All shadoufs appear to approximate very closely to the figures here reported. We found that the bucket holds about $60 \mathrm{lb}$. of water when nearly full, as in the lift, and is raised Ir feet $6 \frac{1}{2}$ times a minute, or up to 8 times a minute for a correspondingly less elevation. Thus the work done in raising the water is about $60 \times \operatorname{II} \times 6.5=4290$ footpounds per minute, or nearly 600 kilogram-metres per minute. Two men, working alternately for about an hour at a time, are employed on each shadouf, and each man works for a total of about 6 hours daily. Thus the work per day is about $1,550,000$ footpounds or 700 foot-tons. The shifts are measured by means of a simple sundial, improvised on the spot. Its essential part is a cord stretched horizontally north and south between the tops of two pegs a few inches above the ground, with marks to indicate the endings of the shifts by the progress of the shadow. The intervals between shifts are devoted to light occupation, meals, and rests.

From other well-known physiological data we may reckon that the gross efficiency of the work during the raising of water is about 20 per cent. As the work done is $x, 550,000$ footpounds, the corresponding amount of energy liberated in the body is therefore equivalent to about $7,750,000$ foot-pounds, serve as a counterpoise. Acting on the short end of the beam it is sufficiently heavy (about $230 \mathrm{lb}$.) to raise a bucket-full of water suspended at the other end.

The bucket consists usually of goat-skin, although light metal buckets of similar size and shape are used in some places, and is held open by a wooden ring about sixteen inches in diameter, and has a cross-bar to which the wooden hook is attached. Since the counterpoise pulls up the water, nearly all the work done by the man is performed in pulling downwards the upright pole carrying the empty bucket. During this operation his body becomes bent to extreme flexion, and has to be straightened as the bucket ascends. He has also to tip the bucket when it reaches the higher level, and just as it reaches the lower level he gives the pole a slight jerk, so as to make the bucket enter the water edgewise, and thus fill instantly.

$$
\text { NO. } 2965 \text {, VOL. I I } 8]
$$
which is equivalent to almost exactly ro,000 British thermal units, or 2500 calories. This is at a rate of about $4 \mathrm{I} 7$ calories an hour, or 7 calories a minute. During the remaining 18 hours of the 24 the average energy liberated cannot well be less than 80 calories per hour, so that the total liberation of energy will be at least 4000 calories. To cover this expenditure the shadouf worker will, if we make the ordinary allowance of to per cent. for waste, require food of the energyvalue of at least 4400 calories.

The men working on the shadoufs are erect and finely developed, looking a picture of health and physical grace, and doing the work without signs of fatigue. They take several meals daily between shifts. These meals consist usually of cakes made fresh each day from maize or wheaten flour, with cheese and sour milk. Hot meals, with lentils or 
beans, and occasional meat, are taken at home. The work could not be kept up day after day if the food were not abundant. We were told that this food is almost entirely the produce of the land the men are irrigating and cultivating. The actual men who work the shadoufs and do the other work on the land are joint farmers. They thus work jointly for themselves and pay the rent jointly, taking all the produce and profits from its sale after the rent has been paid. The rents seem enormous by British or American standards, but the land, as actually worked, is extremely productive. It is very improbable that if the men were working on daily or weekly wages they would work so effectively or obtain the same net earnings. It seems also to be for essentially the same reasons that modern power-driven appliances have not displaced the shadouf. A shadouf is not only extremely efficient mechanically, but can be made from materials on the spot, and can be at any time repaired by the men who use it. To judge from carvings on a tomb near Luxor, the shadouf was practically the same more than three thousand years ago as it is now.

The work done on a shadouf is of special physiological interest, because it is so well standardised, employs so many muscles, and is so easily measured directly. In most kinds of standardised work we can only measure the work indirectly from the oxygen-consumption. In the late Mr. Jervis Smith's book on "Dynamometers" (edited by Prof. Boys) a description is given, on page Io, of another easily measured form of standardised human muscular work. This form of work was employed early last century in raising the earth needed in the construction of forts round Paris. The earth was loaded into a bucket attached to a rope passing over a pulley, and was then drawn up by the action of a counterpoise consisting of a man, whose work consisted in continuously ascending a ladder and coming down as a counterpoise to the ascending earth. It was found that the work done in this way amounted to 4230 foot-pounds per hour-a figure very close to ours for the shadouf worker as regards the rate per hour, though the French navvies kept up this rate during eight hours daily.

There can be no doubt that where the motive is adequate a man in good physical training, and fed in correspondence with the work, can keep up day after day, for say eight hours, a considerably greater rate of measured work than corresponds to these figures; and for short periods far greater rates are possible. Thus Henderson and Haggard (Amer. Journ. of Physio$\log y, 72$, p. 264, 1925) found that over a four-mile race in 22 minutes each oarsman of a university crew did average measured work at a rate of 0.45 . horsepower, or 15,000 foot-pounds a minute, with a total energy-expenditure of 19 calories a minute, or at the rate of II 40 calories per hour. This rate is $3^{\frac{1}{2}}$ times that of the shadouf workers, but, of course, could not be kept up nearly so long. In a $\mathrm{I}_{4}^{1}$ mile rowing race the rate rose to 0.57 horse-power, or 18,770 foot-pounds a minute. For very short periods of less than a minute, still higher rates are possible, even for an untrained man. For example, Douglas and Haldane, with the view of producing maximum discharges of lactic acid from muscles during their temporary lack of oxygen, used short bursts of climbing work at a rate of 30,000 foot-pounds per minute (Journ. of Physiology, 38, p. 43I, I909). The rates of work of the shadouf men and of the French navvies are, however, worthy of record, as these rates could, without unusual effort, be maintained day after day throughout the working period.

We have pleasure in acknowledging the help we received from Mr. George Gattas, of Luxor, a chief dragoman on Messrs. Cook's Nile Service steamers.

\section{Audibility of Explosions and the Constitution of the Upper Atmosphere.}

By F. J. W. Whipple.

DHYSICISTS who are interested in the problem of the temperature and constitution of the upper atmosphere have been awaiting with some impatience the publication of the official reports on the audibility of the experimental explosions arranged by the International Commission for Investigations on the Sound of Explosions. The first experiment was made (at Oldebroek in Holland) in October 1922, but the full report on the second experiment or series of experiments has appeared first. This report ${ }^{1}$ has been prepared by Prof. Charles Maurain, head of the Institut de Physique du Globe at Paris. Some idea of the mass of evidence that has been digested may be gathered from the facts that 405 observations were plotted on the map showing the audibility of the first explosion, 360 and 240 on the maps for the second and third.

The site of the explosions was at La Courtine; this place is about half-way between Paris and the Pyrenees ; as it is more than $250 \mathrm{~km}$. from the nearest sea, the audibility in all directions could be investigated. There were four explosions, on May I 5, 23, 25, and 26,

1 Annales de l'Institut de Physique du Globe. Fascicule spécial consacré aux expériences de La Courtine sur la Propagation des ondes aériennes. Patis, 1926.

$$
\text { NO. } 2965 \text {, VOL. I I } 8]
$$

x924. In each of the first two, about ten tons of melanite was spent, in each of the others, five tons. Observers did not receive sufficient warning in the last case, and M. Maurain's report is practically confined to the other three.

The great advantage of organisation is manifest throughout the report. When explosions have occurred by accident, the places at which they were heard have in many cases been mapped successfully, but accurate records of the time have been raré. With an experimental explosion the observers are ready to note the time to a second at which the sound reaches them. In many of the places from which Prof. Maurain received reports, the agreement between the observers was excellent. Perhaps the best example of precision is provided by the observations at Bordeaux on the first occasion. In the observatory and near by, four observers gave the time as I9 h. 44 m. $5 \mathrm{~s}$., two gave I9 h. $44 \mathrm{~m} .4 \mathrm{~s}$, , and one ig h. $44 \mathrm{~m} .3 \mathrm{~s}$.

Another advantage is that full information can be obtained as to the meteorological conditions. There were at least two soundings of the upper air in France on each of the three 'La Courtine' days, and the stratosphere was reached on each occasion. Special 